Administration, is viewed by some as an across-the-board threat to the pharmaceutical industry. It appears quite possible, however, that these changes could actually favor many emerging pharmaceutical companies, because managed care, by focusing on overall patient outcomes and overall costs, should find favor with novel therapeutics that represent major advances in treatment efficacy and are cost effective. Those are precisely the features that are reasonable to expect in a number of coming, new biopharmaceuticals, such as Synergen's Antril.

For example, in phase II testing, surviving patients who received the most effective dose of Antril spent an average of nine fewer days in the hospital and six fewer days in the intenstive-care unit than surviving patients who received the placebo.

Managed care's probable impact over time on pharmaceutical marketing should also benefit the small companies. The trend toward the concentration of drug purchasing power in hospital associations and other buying groups should mean that sales forces for hospital-used products can be smaller. That would put proprietary marketing of products - as opposed to marketing joint ventures or licensing arrangements-within reach of more emerging companies.

Finally, managed care and its focus on prices will also make it far more difficult in the future for large pharmaceutical companies to increase earnings through price increases. That means earnings growth will have to come increasingly, if not overwhelmingly, from increases in unit consumption. The best way to attain that will be through the development of better drugs.

Hence, the large-capitalization pharmaceutical companies likely to prosper most in coming years will be those with the best research-anddevelopment pipelines. Companies without strong pipelines may be looking more and more this year to the emerging companies for products. Whether that will translate into acquisitions, semi-acquisitions, or partnerships is unknowable, but it seems likely that some cash will move from the large caps in the direction of the small caps in 1993.

\title{
CF researchers fight license
}

LONDON-European researchers working with the gene for cystic fibrosis (CF) are fighting demands that they pay a $\$ 5,000$ licensing fee, plus future royalties, to the Toronto Hospital for Sick Children (Toronto) and the University of Michigan (Ann Arbor, MI). In 1989, the two institutions filed world-wide patents on the CF gene and a number of therapeutic and diagnostic applications, following publication of research that demonstrated the most common CF mutations and gave their DNA sequence.

The two institutions have sent out around 30 requests for payment in the U.S. and Europe, mostly to drug companies wanting to produce diagnostic kits. University and independent laboratories running screening programs have also been targeted, albeit with a lesser licensing fee. Although the patents have yet to be granted, the institutions anticipate no problems. In fact, five licences are already in place.

While the U.S. commercial screening sector has taken this demand in stride, many European researchers have objected, because they work in non-profit, public-service institutions like hospitals and universities. Some researchers fear that if they have to pay a licensing fee for the CF gene, a precedent may be set for other genes.

As the most frequently inherited single-gene disorder, $\mathrm{CF}$ is an attractive candidate for population screening. There is no accepted figure for the size of the world CF screening market, as much depends on which countries opt for population screening. However, the U.S. Congress's Office of Technology Assessment (Washington, DC) estimates that 6 million pregnancies each year could be screened for CF status in the U.S. A complete survey of Americans of reproductive age would involve 125 million people. Since the frequency of the CF gene is highest in individuals of Caucasian descent or European descent, the potential for a screening industry in Europe is at least comparable.

IG Laboratories (Framingham, MA) has a headstart on CF screening. The company, which is 70 percent owned by Genzyme (Cam- bridge, MA), recently introduced a $\$ 100$ diagnostic test for CF that eliminates the need to draw patient blood. The DNA-based test-which detects 12 CF mutations and has an 84 percent detection rate-is performed on cells obtained by brushing the inside of a patient's cheek.

George Chaisson, associate research director of the Hospital for Sick Children's Research Institute, says that his institution has no intention to make a huge profit from the licenses. "It cost a great deal of money to get this thing moving, and hopefully we can recover our costs, but we're not anticipating a hell of a lot else at the moment," he says. The research itself was almost entirely covered by charities in the U.S. and Canada.

As yet, Britain has seen the only coordinated response to the licensing effort. When the draft license forms began to arrive in the summer, the Clinical Molecular Genetics Society (CMGS, Manchester, U.K.), an organization representing the interests of hospital diagnostic laboratories, circulated copies to its members and also to U.K. government lawyers. "We're not clear what the legal situation is," says Andrew Read, CMGS's chairman. "We don't know exactly what the patent covers and whether it will be enforceable in the U.K."

The majority of British laboratories doing CF screening are in $\mathrm{Na}$ tional Health Service (NHS) hospitals, and although money changes hands within the NHS, no profit is made. This means there are no funds to pay for the licenses. The issue is further complicated by the fact that these laboratories are receiving government and charity grants to carry out $\mathrm{CF}$ research.

If there is no legal way around the patents, CMGS's Read intends to appeal directly to the researchers involved-Lap-Chee Tsui in Toronto and Francis Collins in Michigan-in the hope that they will defer or discount the licensing payments. A final option might be for the national health authorities, such as the U.K. Department of Health (London), to negotiate umbrella licenses for all their laboratories.

-Ian Mundell
European

researchers

fear that

paying a

CF-gene

licensing fee

may set a

precedent for

other genes. 